\title{
Comprehensive Evaluation and Analysis of Urban Rail Transit Network Plan Based on DEA Method
}

\author{
ZHANG Yu-zhao, WANG Jian-qiang \\ School of Traffic and Transportation, Lanzhou Jiaotong University, Lanzhou730070, China \\ yuzhaozhang@126.com, xinxiwjq@126.com
}

Keywords: Urban rail transit, network plan, comprehensive evaluation, DEA

\begin{abstract}
The evaluation of urban rail transit plan network is the key link of rail transit plan, it is very important for determining optimal plans or satisfying plans which are advanced in technology, reasonable in economy, and feasible in implementation. Based on the analysis of present evaluation index systems and evaluation methods of urban rail transit plan network, the index system is optimized, and the evaluation model of urban rail transit plan network is established by applying DEA method with its solution method is given. Finally, a case is applied to show the feasibility of the method, which can provide basis for determining the optimal scheme of urban rail transit network plan. The research shows that there are many advantages by DEA method to evaluate urban rail transit network plan, which can provide reference for decision-maker to choose schemes.
\end{abstract}

\section{Introduction}

Evaluation of urban rail transit network plan is a vital link. It has very important significance for determining optimal or satisfying schemes [1]. The researches on evaluation of urban rail transit network plan in developed countries primarily concentrate on qualitative analysis, while relatively lack of quantitative analysis [2]. Representative researches in China mainly include three aspects, one is aiming at the establishment of evaluation index system [2,3], the second one is in view of the evaluation methods of urban rail transit network plan [4,5], and the third one is the integrated study [6]. Although above research have a certain role in unifying the evaluation standard, there are also some problems. For example, for index system, the scale is too large to put into practical application easily, meanwhile, some indexes are difficult to get so that the maneuverability is bad. For evaluation methods, the comprehensive benefit of each scheme can not be reflected because of the input and output being not considered synthetically. Based on above study, the evaluation index system is established. Then, the evaluation model based on DEA method is put forward, which can provide scientific basis for evaluation of urban rail transit network plan.

\section{Establishment of Evaluation Index System}

Index system is the basis of evaluation, so it must reflect the synthetic performance of alternatives, as well as has good maneuverability. The target of urban rail transit system is to improve urban traffic network, increase traffic capacity, and enhance the travelling accessibility and travelling speed of president. Meanwhile, the social cost must be saved, while land utilization and external traffic devices must be coordinated. Furthermore, the plan scheme should also be easy to carry out. It shows that the targets include five aspects, operation effect, network structure, social effect, strategic development and constructing implementation.

To analyze and evaluate urban rail transit network plan adopting Data Envelopment Analysis (DEA) method, each alternative scheme can be taken as a decision-making unit (DMU), and the input indexes and output indexes should be determined. Therefore, in the premise of reflecting the characteristic of urban rail transit network plan, we analyze and merge the indexes by principal component analysis method so that the operability can be improved. The input indexes and output indexes are determined as table 1. 
Table 1 Input and output index system of urban rail transit network plan

\begin{tabular}{|c|c|c|}
\hline $\begin{array}{c}\text { Serial } \\
\text { number }\end{array}$ & classes & Evaluation indexes \\
\hline \multirow[t]{4}{*}{ 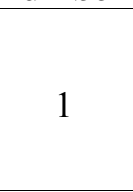 } & \multirow{4}{*}{$\begin{array}{c}\text { Input } \\
\text { indexes }\end{array}$} & Network scale \\
\hline & & Difficulty of project \\
\hline & & Non- linear coefficient \\
\hline & & Coefficient of transfer \\
\hline \multirow{6}{*}{2} & \multirow{6}{*}{$\begin{array}{l}\text { Output } \\
\text { indexes }\end{array}$} & Average passenger volume of rail transit \\
\hline & & Ratio of rail traffic within public traffic \\
\hline & & Save of trip time by rail transit \\
\hline & & Number of connection with large passenger distributed point \\
\hline & & Ratio of covering central area \\
\hline & & Coincided degree with land utilization \\
\hline
\end{tabular}

The indexes in table 1 not only comprehensively consider operation, service, effect, development and constructing implementation of urban rail transit, but also are easy to get.

\section{Evaluation Model of Urban Rail Transit Network Plan Based on DEA Method}

The most basic model of DEA is $C^{2} R$ model. However, when evaluating the DEA efficiency of decision-making unit, it is difficult to solve the model sometimes. So the $C^{2} R$ model with non-archimedean infinitesimal amount is introduced [7]. Suppose the number of decision-making unit $\mathrm{DMU}_{j}(j=1,2, \ldots, n)$ is $n$. The input vector of $\mathrm{DMU}_{j}$ is $x_{j}=\left(x_{1 j}, x_{2 j}, \ldots, x_{\mathrm{m} j}\right)$, while the output vector is $y_{\mathrm{j}}=\left(y_{1 j}, y_{2 j}, \ldots, y_{s j}\right)$, where, $\mathrm{m}$ and $\mathrm{s}$ expresses the number of input and the number of output respectively, according to above index system, we know that $m=4$, and $s=6$. Meanwhile, $\left(x_{j}, \mathrm{y}_{\mathrm{j}}\right) \in T$, and $x_{j} \geq 0, \mathrm{y}_{\mathrm{j}} \geq 0 . T$ is the set of schemes. Suppose $\varepsilon$ is the non-archimedes infinitesimal content, then the evaluation model of urban rail transit network plan is as model (1).

$$
\begin{gathered}
\min \left[\theta-\varepsilon\left(\hat{e}^{\mathrm{T}} s^{-}+e^{\mathrm{T}} s^{+}\right)\right] \\
\text {s.t. }\left\{\begin{array}{c}
\sum_{j=1}^{n} x_{j} \lambda_{j}+s^{-}=\theta x_{0} \\
\sum_{j=1}^{n} y_{j} \lambda_{j}-s^{+}=y_{0} \\
\lambda_{j} \geq 0 \quad(j=1,2, \cdots, n) \\
s^{-} \geq 0, \quad s^{+} \geq 0 .
\end{array}\right.
\end{gathered}
$$

In the model, $S$ is surplus variable, which means input redundancy, while $S^{+}$is slack variable which means output shortfall. $\lambda_{j}$ expresses the weight of the $j$-th decision-making unit. Furthermore, $\hat{e}^{T}=(1,1, \ldots, 1) \in E_{m}, e^{T}=(1,1, \ldots, 1) \in E_{s}$. Suppose the optimized solution of problem (1) is $\lambda^{0}, s^{0-}, s^{0+}$ and $\theta^{0}$. If $\theta^{0}=1$, and $s^{0-}=0, s^{0+}=0$, then the decision-making unit $\mathrm{DMU}_{j}$ is DEA efficient. Otherwise if $\theta^{0}=1$, but $s^{0-} \neq 0$ or $s^{0+} \neq 0$, then the decision-making unit $\mathrm{DMU}_{j}$ is weak DEA efficient. If $\theta^{0}<1$, then $\mathrm{DMU}_{j}$ is non-DEA effective.

The programming realization of the model is by Lingo9.0. According to the Lingo program and corresponding sample data, not only the optimal scheme of urban rail transit network plan could be obtained, but also the non-efficient reason of other schemes would be analyzed, which can provide references for decision makers.

\section{Case study}

There are five alternative schemes of urban rail transit network plan in a city, the index values of each scheme are as table 2, we can analyze and evaluate these schemes adopting above model, and then determine the optimal scheme. 
Table 2 Input and output index value

\begin{tabular}{|c|c|c|c|c|c|c|c|c|c|c|c|}
\hline \multirow{2}{*}{\multicolumn{2}{|c|}{ Index value }} & \multicolumn{4}{|c|}{ Input index } & \multicolumn{6}{|c|}{ Output index } \\
\hline & & \multirow{2}{*}{$\begin{array}{c}x_{1 j} / \\
\mathrm{km}\end{array}$} & \multirow{2}{*}{$\begin{array}{c}x_{2 j} \\
0.73\end{array}$} & \multirow{2}{*}{$\begin{array}{c}x_{3 j} \\
1.29\end{array}$} & \multirow{2}{*}{$\begin{array}{c}x_{4 j} \\
1.38\end{array}$} & \multirow{2}{*}{$\begin{array}{c}y_{1 j} \\
618.4\end{array}$} & \multirow{2}{*}{ 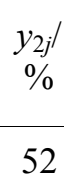 } & \multirow{2}{*}{$\begin{array}{c}y_{3 j} / \\
10^{4} \mathrm{~h} / \mathrm{d} \\
118.4\end{array}$} & \multirow{2}{*}{$\begin{array}{l}y_{4 j} \\
40\end{array}$} & \multirow{2}{*}{$\begin{array}{c}y_{5 j} \\
0.68\end{array}$} & \multirow{2}{*}{$\begin{array}{c}y_{6 j} \\
0.70\end{array}$} \\
\hline \multirow{5}{*}{ scheme } & 1 & & & & & & & & & & \\
\hline & 2 & 201.2 & 0.80 & 1.35 & 1.36 & 622.5 & 52 & 120.3 & 42 & 0.70 & 0.71 \\
\hline & 3 & 182. 3 & 0.65 & 1.15 & 1.30 & 605.6 & 51 & 125.5 & 41 & 0.75 & 0.75 \\
\hline & 4 & 195.8 & 0.76 & 1.32 & 1.40 & 615.2 & 51 & 119.2 & 41 & 0.73 & 0.72 \\
\hline & 5 & 190. 5 & 0.75 & 1.28 & 1.35 & 608.5 & 50 & 114.6 & 40 & 0.65 & 0.68 \\
\hline
\end{tabular}

According to the index system as well as the established DEA model, the results are solved by programming applying Lingo9.0 software, which are shown in table 3.

Table 3 Operating results

\begin{tabular}{|c|c|c|c|c|c|}
\hline $\begin{array}{c}\text { Operating } \\
\text { results }\end{array}$ & 1 & 2 & 3 & 4 & 5 \\
\hline$\theta^{*}$ & 0.96181 & 0.95434 & 1.00000 & 0.89457 & 0.96742 \\
\hline \multirow{5}{*}{$\mathrm{S}^{*-}$} & 0.55941 & 10.30325 & 0.00000 & 0.00000 & 1.14993 \\
\cline { 2 - 6 } & 0.03848 & 0.11791 & 0.00000 & 0.05851 & 0.07257 \\
\cline { 2 - 6 } & 0.06659 & 0.14436 & 0.00000 & 0.08024 & 0.08299 \\
\cline { 2 - 6 } & 0.00000 & 0.00000 & 0.00000 & 0.00353 & 0.00000 \\
\hline \multirow{5}{*}{$\mathrm{S}^{+}$} & 0.00000 & 0.00000 & 0.00000 & 0.00000 & 0.00000 \\
\cline { 2 - 6 } & 0.07794 & 0.42322 & 0.00000 & 0.80845 & 1.24422 \\
\cline { 2 - 6 } & 9.75258 & 8.70223 & 0.00000 & 8.28943 & 11.50097 \\
\cline { 2 - 6 } & 1.86658 & 0.14415 & 0.00000 & 0.64993 & 1.19633 \\
\cline { 2 - 6 } & 0.08585 & 0.07093 & 0.00000 & 0.03189 & 0.10359 \\
\hline$\sum \lambda *$ & 0.06585 & 0.06093 & 0.00000 & 0.04189 & 0.07359 \\
\hline
\end{tabular}

The operating results show that: for scheme $3, \theta^{*}=1$, meanwhile, $\mathrm{S}^{*^{-}}=0, \mathrm{~S}^{*^{+}}=0$, so the technical optimization and scale optimization are both realized. However, for scheme 1, scheme 2, scheme 4 and scheme 5 , the value of $\theta^{*}$ is respectively $0.96181,0.95434,0.89457$ and 0.96742 , thus these four schemes are all non efficient. Moreover, $\sum \lambda^{*}$ respectively equals $1.02432,1.21323$, 1.04367 and 1.02134, and they are all greater than 1, which expresses that the scale benefit is decline, that is, based on original inputs, the increasing of input can not lead to more proportion of output. Therefore, it is unnecessary to add the input of decision-making unit.

From above analysis we can see that the optimal scheme is scheme 3. For the other four schemes, although the proportion of output can not be enhanced by increasing input, it is impossible to achieve DEA efficient by reducing input scale and increasing output so that the efficiency of input-output can be improved. Taking scheme 5 as example, if the network scale was reduced $1.14993 \mathrm{~km}$, the project difficulty was decreased 0.07257 , and non-linear coefficient was reduced 0.08299 , while the ratio of rail traffic within public traffic and save of trip time by rail traffic was respectively improved $1.24422 \%$ and $11.50097 \times 10^{4} \mathrm{~h} / \mathrm{d}$, this scheme would be DEA efficient.

\section{Conclusions}

DEA is an excellent non-parameter evaluation method, especially for the evaluation and analysis of multi-input-multi-output problem. Introducing DEA method to evaluate and analyze the urban rail transit network plan, not only the optimal scheme can be obtained, but also the reason of non-optimal and the adjusting method of relative non-optimal scheme would be analyzed. According to the case study of the urban rail transit network plan, it shows that all the input and output can be comprehensively considered, while the operation of DEA model for urban rail transit network plan is simple. The urban rail transit network plan refers to enormous aspects and be 
difficult to evaluate quantitatively, so we will go on optimizing the index system in future so that the evaluation result can be more reasonable and objective.

\section{Acknowledgment}

This work was supported in part by Humanities and Social Science Foundation of Ministry of Education of China under Grant No.12YJC630200, and by the Young Scholars Science Foundation of Lanzhou Jiaotong University under Grant No.2012031.

\section{References}

[1] MAO Bao-hua. Urban Transit Planning and Design [M]. Beijing: China Communications Press, 2006

[2] JI Jia-lun, LI Fu-zhi. Study on the Synthetic Evaluation Index System of Urban Rail Transit Line Network Planning Scheme [J]. System Engineering Theory and Practice, 2004(3):129-133

[3] DU Sheng-pin, KONG Jian-yi, XIONG Ling. Research on Evaluation Index System of Urban Transit Network Planning Scheme [J]. Journal of Wuhan University of Technology, 2003, 27(6): 841-844

[4] MENG Xing-ding, WU Xiao-ping. Grey Fuzzy Comprehensive Evaluation of Urban Rail Transit Network[J]. Journal of Quest, 2007(6): 21-23

[5] MA Chao-qun. Comprehensive Evaluation for Urban Rail Transit Network Based on Grey Weight Relation [J].Journal of Chang' an University(Natural Science Edition). 2007, 27(3):84-87

[6] ZHOU Hou-wen. Research on the Intercity Rail Transit Network Plan for Pearl River Delta Region[J]. Journal of Railway Engineering Society, 2009(8):96-100

[7] WEI Quan-ling. Data Envelopment Analysis[M]. Beijing: Science Press, 2004 